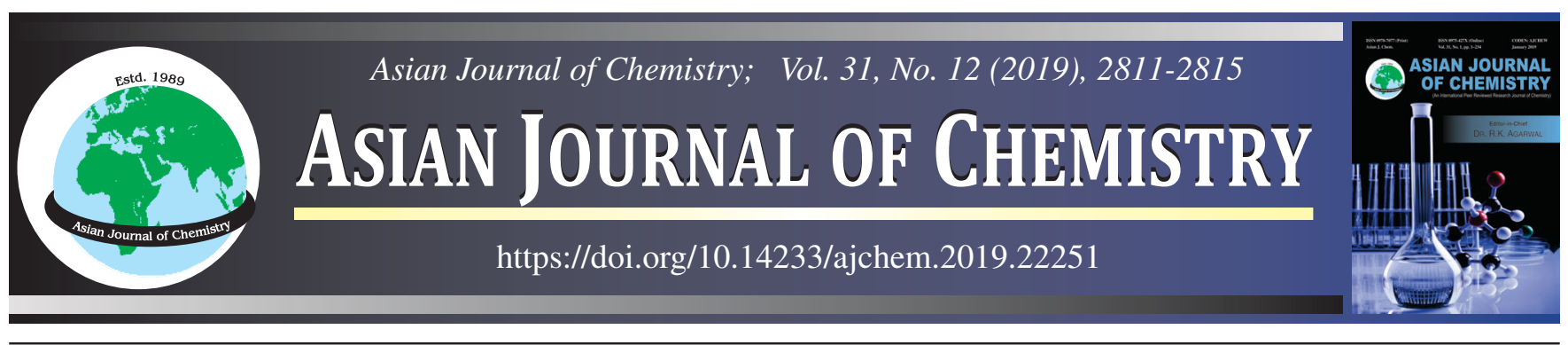

\title{
Biosynthesis and Characterization of Bioplastic Poly-3-hydroxybutyrate from Hydrolyzate of Ulva using Bacillus subtilis rnM
}

\author{
T. REVADHI ${ }^{*}{ }^{\oplus}$ and R. NANTHINI ${ }^{\circledR}$
}

Post Graduate and Research Department of Chemistry, Pachaiyappa's College, Chennai-600030, India

*Corresponding author: E-mail: revetheet@yahoo.co.in

Received: 10 June 2019;

Accepted: 12 July 2019;

Published online: 16 November 2019;

AJC-19624

\begin{abstract}
Biopolymers are a new generation biopolymers, which have wide range of applications. Poly-3-hydroxybutyrate (PHB) is one of the best biopolymers for replacement of non-biodegradable petroleum-based plastic and can be produced from organic wastes source by some bacterial strains under imbalance growth conditions. In present study, hydrolyzate was prepared from biomass of seaweed $U l v a$ by acid pre-treated and used as a feedstock for PHB biosynthesis by Bacillu subtilis rnM. The pre-treatment was carried out by two different pretreatment conditions such as room temperature and high temperature and pressure (HTP). The hydrolysate prepared by $2 \% \mathrm{HCl}$ at $\mathrm{HTP}$ supported for the maximum PHB biosynthesis than the other pre-treated conditions. The yield of PHB obtained by $B$. subtilis rnM when tested with laboratory grade sugars was lower to that achieved with hydrolysate of Ulva sp. The biosynthesized PHB was characterized by TGA, DSC, FTIR, XRD and NMR techniques.
\end{abstract}

Keywords: Poly-3-hydroxybutyrate, Bacillus subtilis rnM, Hydrolyzate, Ulva.

\section{INTRODUCTION}

In recent years the plastics consumption is increased due to fast growth in population, industrialization and urbanization. The majority of plastics and synthetic polymers are made from petrochemicals and are not biodegradable, thus resulting in the environmental pollution. They are thus not sustainable from both a production and end of life management perspective [1]. The use and disposal of plastics has threatened natural environment, all over world. Therefore, biopolymers (environmentally degradable polymers) are considered as a suitable alternative candidate for petroleum-based plastics due to their properties includes non-toxicity, completely biodegradability and biocompatibility [2]. Among the various types of biopolymers, poly-3hydroxybutyrates (PHBs) are the most well known, being recognized as biosynthetic, biodegradable with zero toxic waste, widely distributed in nature, recyclable into organic waste and can be made from renewable resources [3]. Poly-3-hydroxybutyrate (PHB) is the most common polyhydroxyalkanoate (PHA) [4].

Currently, increasing regulations to ban the plastic bags, other single-use plastic items included drinking straws and using biodegradable plastics in biomedicine, food industry, microelectronics, malt extrusion industries, film formation, etc. [5], are driving growing demand for biodegradable polymers (BDP). In the year 2018, market value of PDB exceeded \$1.1 billion and it could reach $\$ 1.7$ billion by 2023 . At present, the global demand for PDB is 360,000 metric tons; total consumption of PDB is expected to increase to almost 550,000 metric tons by 2023 [6]. A wide variety of bacteria, under nutrient imbalanced condition, they can accumulate PHB as a carbon and energy storage materials $[7,8]$. However, one of the major constraints of large-scale PHB production is the cost of carbon substrate for PHB biosynthesizing microbes. Therefore, the use of low-cost carbon sources as substrate can reduce the PHB production cost. The most important approach to reduce costs is using wastes and by-products as substrate for the PHB synthesis process. Some novel technologies have been developed to synthesize PHB from organic wastewater and activated sludge. Hence, replacement of petroleum-based plastics with biodegradable plastic from organic waste can contribute to sustainable development of environment [3,9].

Sugar and starch have been used as simple carbon sources to produce PHAs at laboratory and industrial scale $[1,10]$. These

This is an open access journal, and articles are distributed under the terms of the Attribution 4.0 International (CC BY 4.0) License. This license lets others distribute, remix, tweak, and build upon your work, even commercially, as long as they credit the author for the original creation. You must give appropriate credit, provide a link to the license, and indicate if changes were made. 
carbon sources are also a primary source of human food. Researchers are seeking non-food carbon resources for PHB production to avoid the competition with human food sources. So many unexplored feedstock's are available. The seaweed is one among that which are distributed worldwide [11]. The widely ranging chemical composition of seaweed biomass is very often used as raw material for the production of different ingredients [12]. First time we made an attempt to produce PHB from crude extract of seaweed Ulva using bacterial strain Bacillus subtilis rnM. This is the common seaweeds distributed worldwide and they containing interesting chemical composition, which makes it commercial exploitation for various product production [13].

The main objective of the present study was to evaluate Ulva sp. biomass as a carbon source for biosynthesis of poly3-hydroxybutyrate (PHB) by B. subtilis rnM. Additionally, the effect of physio-chemical pre-treatments on conversion of seaweed Ulva biomass into simple sugars and their subsequent conversion to PHB by B. subtilis rnM was examined. The growth and PHB biosynthesis by $B$. subtilis $\mathrm{rnM}$ on hydrolyzate was compared to commercial simple sugars and mixed sugars. The biosynthesized PHB was characterized.

\section{EXPERIMENTAL}

The chemicals used in the experiment for preparing various media were of highest purity/analytical grade and purchased from E-Mecrk India Ltd. Bacillus subtilis rnM mutant type strain was used for poly-3-hydroxybutyrate (PHB) biosynthesis throughout this study. Before using this bacterium was maintained in nutrient agar slant and stored at $4{ }^{\circ} \mathrm{C}$ and revived after every month.

Hydrolyzate of seaweed Ulva sp. biomass: The seaweed Ulva sp. was freshly collected from Tamil Nadu costal area of Southern India and thoroughly washed in tap water followed by distilled water. Then, the seaweed biomass was chopped into small pieces and used for hydrolyzate preparation by $\mathrm{HCl}$ pretreatment. For pre-treatment experiments, the solid loading of the seaweed was kept constant at $6 \%(\mathrm{w} / \mathrm{v})$. The concentrations of $\mathrm{HCl}$ used were $1-3 \%$. Two different pre-treatment conditions were tested; room temperature and high temperature and pressure (HTP). The mixture of $\mathrm{HCl}$ and seaweed was agitated at 200 $\mathrm{rpm}$ for $24 \mathrm{~h}$ at room temperature $\left(28 \pm 2{ }^{\circ} \mathrm{C}\right)$. Pre-treatment using a combination of $\mathrm{HCl}$ and $\mathrm{HTP}$ was performed in an autoclave unit, whereby the mixture of seaweed and $\mathrm{HCl}$ was pretreated at $121{ }^{\circ} \mathrm{C}$ and $0.1 \mathrm{MPa}$ for $15 \mathrm{~min}$. Before filtration, samples were neutralized using $1 \mathrm{M} \mathrm{NaOH}$. Then the filtered hydrolyzate was stored and used as a feedstock for PHB biosynthesis by $B$. subtilis $\mathrm{rnM}$. Three independent experiments were carried out for each pre-treatment conditions. Data were analyzed using the statistical software package-MINITAB 17 to determine the effects of various pre-treatments on digestibility of the Ulva biomass and yield of sugars.

Biosynthesis of poly-3-hydroxybutyrate (PHB) using laboratory grade sugars and hydrolyzates: The mutant strain B. subtilis rnM was initially screened for its abilities to utilize different monomeric sugars present in the Ulva biomass such as arabidose, galactose, glucose, mannose, rhamnose, xylose and uronic acids individually as sole carbon and energy source for growth and PHB accumulation. Additionally, a mixture of sugars similar to the composition of hydrolyzate was tested for sugar co-utilization studies. Similarly, filtered sterilized hydrolyzate was added to $100 \mathrm{~mL}$ mineral salt medium (MSM). The experiments were carried out in $250 \mathrm{~mL}$ shaking flasks using $100 \mathrm{~mL}$ of nitrogen limited $\left(0.25 \mathrm{~g} / \mathrm{L} \mathrm{NH}_{4} \mathrm{Cl}\right) \mathrm{MSM}$ with $3.5 \mathrm{~g} \mathrm{~L}^{-1}$ of final sugar concentration. Then the medium was inoculated with $1 \%$ of $B$. subtilis $\mathrm{rnM}$ and incubated for $48 \mathrm{~h}$ in a rotary shaker at room temperature $\left(28 \pm 2^{\circ} \mathrm{C}\right)$ and $150 \mathrm{rpm}$. The experiments were carried out in triplicate for each study. All values are represented as mean \pm SD of three replications. The standard deviation did not exceed $5 \%$ of the average values.

Estimation of total reducing sugars and analysis of monosaccharide: The sugar concentration of hydrolyzates and culture supernatant was estimated by dinitrosalicylic (DNS) acid method [14]. Monosaccharide composition of hydrolyzate was determined by anion exchange chromatography using a Dionex ICS-300 system (Thermo Scientific CA, USA) equipped with a gold electrode and amperometric detector. The column was a CarboPac SA10 $(4 \times 250 \mathrm{~mm})$ equipped with a security guard cartridge. The sample was eluted with $1 \mathrm{mM} \mathrm{KOH} \mathrm{under}$ isocratic condition at $1 \mathrm{~mL} / \mathrm{min}$ and $25^{\circ} \mathrm{C}$. The appropriate monosaccharide standards (arabidose, galactose, glucose, mannose, rhamnose, xylose and uronic acids) were used as a reference for quantification. An appropriate dilution of the water soluble hydrolyzate or culture supernatant was prepared. The sample $(0.5 \mathrm{~mL})$ was filtered by Whatman Mini-UniPrep ${ }^{\mathrm{TM}}$ syringeless filters $(0.45 \mu \mathrm{m}$ Whatman Inc. NJ, USA) and a 10 $\mu \mathrm{L}$ of sample was used for all injections.

Determination of cell dry weight (CDW): The bacterial cells were harvested by centrifugation at $8000 \mathrm{rpm}$ for $10 \mathrm{~min}$. Then the pellet was collected and washed with distilled and lyophilized. The lyophilized cells weight was determined and the CDW was expressed in $\mathrm{g} \mathrm{L}^{-1}$.

Extraction and estimation: Poly-3-hydroxybutyrate (PHB) was extracted and estimated according to Koller $\mathrm{et} \mathrm{al.}$ [15] and Law and Slepecky [16] method, respectively.

Thermal transitions of poly-3-hydroxybutyrate (PHB) was characterized by differential scanning calorimetry (TA Instruments Q100, USA) and TGA was performed on a PerkinElmer TGA 4000. The chloroform extract of PHB (4 mg) was mixed thoroughly with $\mathrm{KBr}$ (spectroscopic grade) and dried at $100^{\circ} \mathrm{C}$ for $4 \mathrm{~h}$. IR spectra of sample was recorded and analyzed on a single beam Perkin-Elmer (Spectrum BX series, Sweden), with the scan in the range of $4000-500 \mathrm{~cm}^{-1}$. The ${ }^{1} \mathrm{H} N M R$ spectra of sample was recorded at room temperature in $\mathrm{CDCl}_{3}(20 \mathrm{mg}$ $\mathrm{mL}^{-1}$ ) using Bruker AV 400 NMR spectrometer (Bruker, Swiss) to determine the chemical structure and monomer composition of sample by Kato et al. [17] method.

\section{RESULTS AND DISCUSSION}

Parameters influencing the conversion of biomass into fermentable sugar by acid pre-treatment: As an initial step, the Ulva biomass was subjected to acid pre-treatment (1-3\% $\mathrm{HCl}$ ) with two different pre-treatment conditions such as room temperature and high temperature and pressure (HTP). As shown in Table-1, the maximum total reducing sugar yield of $416.33 \pm 33 \mathrm{mg} \mathrm{g}^{-1}$ was obtained from using $2 \% \mathrm{HCl}$ at HTP, 


\begin{tabular}{|c|c|c|c|c|}
\hline \multicolumn{5}{|c|}{$\begin{array}{l}\text { TABLE-1 } \\
\text { ACID PRE-TREATMENT OF Ulva BIOMASS FOR } \\
\text { EXTRACTING TOTAL REDUCING SUGARS }\end{array}$} \\
\hline \multirow[b]{2}{*}{ Treatments } & \multicolumn{2}{|c|}{ Room temperature } & \multicolumn{2}{|c|}{$\begin{array}{l}\text { High temperature and } \\
\text { pressure }\end{array}$} \\
\hline & $\begin{array}{l}\text { Solids } \\
\text { recovered } \\
\quad(\%)\end{array}$ & $\begin{array}{l}\text { Sugar } \\
\text { produced } \\
(\mathrm{mg}) / \mathrm{raw} \\
\text { biomass }(\mathrm{g})\end{array}$ & $\begin{array}{l}\text { Solids } \\
\text { recovered } \\
\quad \%)\end{array}$ & $\begin{array}{l}\text { Sugar } \\
\text { produced } \\
(\mathrm{mg}) / \mathrm{raw} \\
\text { biomass }(\mathrm{g})\end{array}$ \\
\hline Control & $100 \pm 0.0$ & $48.21 \pm 0.56$ & $2.01 \pm 0.45$ & $114.01 \pm 0.34$ \\
\hline $1.0 \% \mathrm{HCl}$ & $5.21 \pm 0.21$ & $325.12 \pm 0.16$ & $1.21 \pm 0.32$ & $415.33 \pm 0.12$ \\
\hline $1.5 \% \mathrm{HCl}$ & $3.21 \pm 0.14$ & $326.21 \pm 0.14$ & $1.01 \pm 0.24$ & $415.32 \pm 0.48$ \\
\hline $2.0 \% \mathrm{HCl}$ & $3.01 \pm 0.21$ & $325.10 \pm 0.12$ & $0.56 \pm 0.14$ & $416.33 \pm 0.33$ \\
\hline $2.5 \% \mathrm{HCl}$ & $2.15 \pm 0.31$ & $325.01 \pm 0.55$ & $0.52 \pm 0.25$ & $415.13 \pm 0.45$ \\
\hline $3.0 \% \mathrm{HCl}$ & $2.15 \pm 0.11$ & $325.06 \pm 0.42$ & $0.55 \pm 0.22$ & $414.89 \pm 0.15$ \\
\hline
\end{tabular}

than room temperature condition using $1.5 \% \mathrm{HCl}(326.21 \pm$ $0.14 \mathrm{mg} / \mathrm{g}$ raw biomass).

The compositional analysis and monosaccharide concentration of hydrolyzates obtained from untreated, $1.5 \% \mathrm{HCl}$ treated at room temperature and $2.0 \% \mathrm{HCl}$ treated HTP of Ulva biomass were given in Table-2. The different hydrolyzates showed it to contain predominantly glucose and rhamnose but it also contained hexoses and pentoses. The maximum yield of both the hexoses and pentoses were observed in hydrolyzate obtained by $2 \% \mathrm{HCl}$ treated HTP. In this pre-treatment maximum glucose concentration of $53.21 \mathrm{~g} / 100 \mathrm{~g}$ total was obtained, than the other monosaccharide. The high concentration of glucose in the hydrolyzate indicated that most of the lignin and a major portion of hemicellulose were removed by acid pre-treatment processes. The hydrolyzate prepared from Ulva biomass by $2.0 \% \mathrm{HCl}$ treated HTP was used for PHB biosynthesis. This is the first attempt we made to use seaweed Ulva biomass hydrolyzate as feedstock for PHB biosynthesis.

Poly-3-hydroxybutyrate (PHB) biosynthesis by B. subtilis rnM using hydrolyzate: This study evaluated $B$. subtilis $\mathrm{rnM}$ strain for its ability to utilize different sugars present in the hydrolyzate obtained by $2 \% \mathrm{HCl}$ treated at HTP. As shown in Fig. 1, the maximum PHB of $43.41 \pm 0.11 \mathrm{~g} \mathrm{~L}^{-1}$ were obtained from HTP hydrolyzate treated $2 \% \mathrm{HCl}$. This yield is slightly higher than commercially purchased simple sugars and mixed sugars tested in this study for PHB biosynthesis. This could be due to some PHB biosynthesis-enhancing component present in the hydrolyzate. Similarly, bacterial growth on hydrolyzate, which indicated the absence of any growth inhibitors [18]. Very less residual sugar $\left(0.02 \mathrm{mg} \mathrm{L}^{-1}\right)$ was detected in culture supernatants after $48 \mathrm{~h}$ of cultivation of test strain in the hydrolysate. A critical and important feature of any effective fermentation process is the assimilation and utilization of these sugars by microorganisms. Various bacterial strains are metabolically versatile and known for its PHA biosynthetic ability from different of organic substrates $[19,20]$.

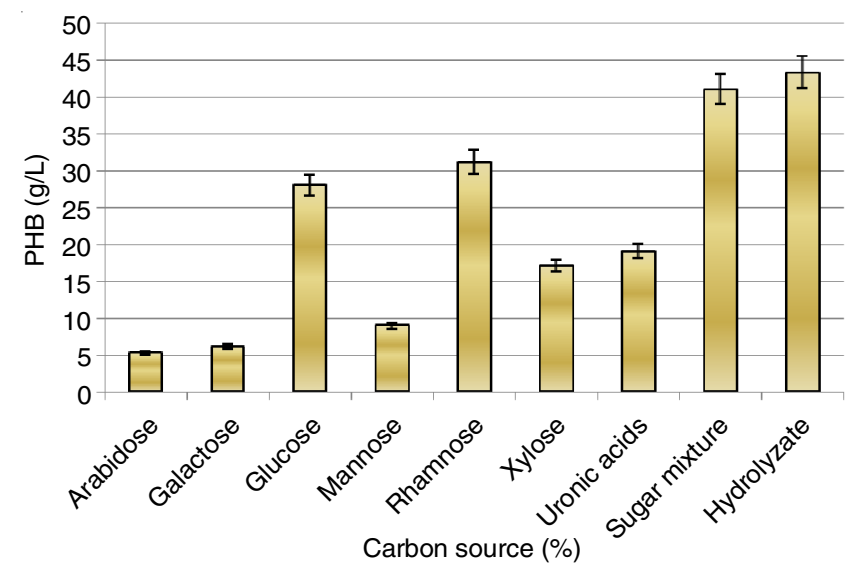

Fig. 1. PHB biosynthesis using hydrolyzate and laboratory grade sugars

FTIR analysis: The FTIR spectra of biosynthesized PHB showed amorphous PHB characteristics (Fig. 2). An absorption peak at $3436.80 \mathrm{~cm}^{-1}$ indicative of presence of hydroxyl group in a polymer chain [21]. The peak at $2978.80 \mathrm{~cm}^{-1}$ was assigned for asymmetric methyl group. The peak at $2834.50 \mathrm{~cm}^{-1}$ was stretching vibration which is allocated to asymmetric $\mathrm{CH}_{2}$ of the lateral monomeric chains. The intensity of the band has suggested that the polymer was less crystalline. Absorption band of $1732.90 \mathrm{~cm}^{-1}$ has been reported to be a PHB marker band which is assigned for carbonyl ester $(\mathrm{RC}=\mathrm{O})$ stretching vibration. Absorption peak at $1284.10 \mathrm{~cm}^{-1}$ was assigned for terminal $\mathrm{CH}_{3}$ groups [21], while the peak at $1187.80 \mathrm{~cm}^{-1}$ was assigned for $\mathrm{C}-\mathrm{O}$ stretching vibration in the amorphous phase.

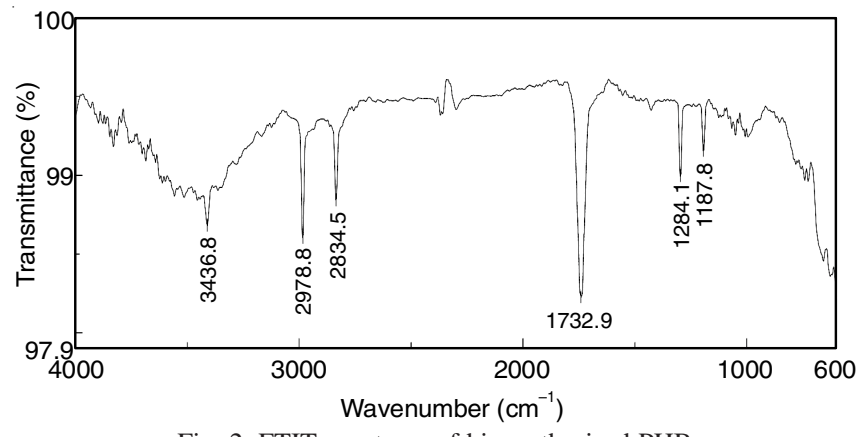

Fig. 2. FTIT spectrum of biosynthesised PHB

${ }^{1} \mathbf{H}$ NMR analysis: The ${ }^{1} \mathrm{H}$ NMR spectrum of PHB was obtained with $\mathrm{CDCl}_{3}$ solution. In Fig. 3, methyl protons $\left(-\mathrm{CH}_{3}\right)$ appear to have a double resonance at $1.50 \mathrm{ppm}$, methylene protons $\left(-\mathrm{CH}_{2}\right)$ appear to have a multiplet resonance at $2.40 \mathrm{ppm}$, methine proton $(-\mathrm{CH})$ of bacterial polyhydroxybutyrate also has a multiplet resonance at $5.20 \mathrm{ppm}$. The ${ }^{1} \mathrm{H}$ NMR spectra implied that the PHB contained the two monomeric units hydroxybutyrate (HB) and hydroxy valerate) (HV). The ${ }^{1} \mathrm{H} N \mathrm{NR}$ spectrum resonances of $\mathrm{P}(\mathrm{HB}-\mathrm{co}-\mathrm{HV})$ at $1.50,2.40$ and $5.20 \mathrm{ppm}$ for $-\mathrm{CH}_{3}$

TABLE-2

MONOSACCHARIDE CONCENTRATIONS OF HYDROLYZATE OBTAINED FROM OPTIMUM PRE-TREATMENTS OF Ulva BIOMASS

\begin{tabular}{lccccccc}
\hline \multicolumn{1}{c}{ Treatments } & \multicolumn{5}{c}{ Monosaccharide composition $(\%)$} \\
\cline { 2 - 7 } & Arabidose & Galactose & Glucose & Mannose & Rhamnose & Xylose & Uronic acids \\
\hline No pre-treatment at room temperature & 0.42 & 3.26 & 35.21 & 1.32 & 31.02 & 2.5 & 10.32 \\
$1.5 \% \mathrm{HCl}$ at room temperature & 1.56 & 4.21 & 48.22 & 1.68 & 39.21 & 3.2 & 12.02 \\
No pre-treatment at HTP & 1.51 & 4.21 & 39.21 & 1.45 & 37.12 & 3.8 & 13.31 \\
$2 \% \mathrm{HCl}$ at HTP & 2.51 & 5.21 & 53.21 & 2.34 & 49.32 & 4.1 & 16.32 \\
\hline
\end{tabular}




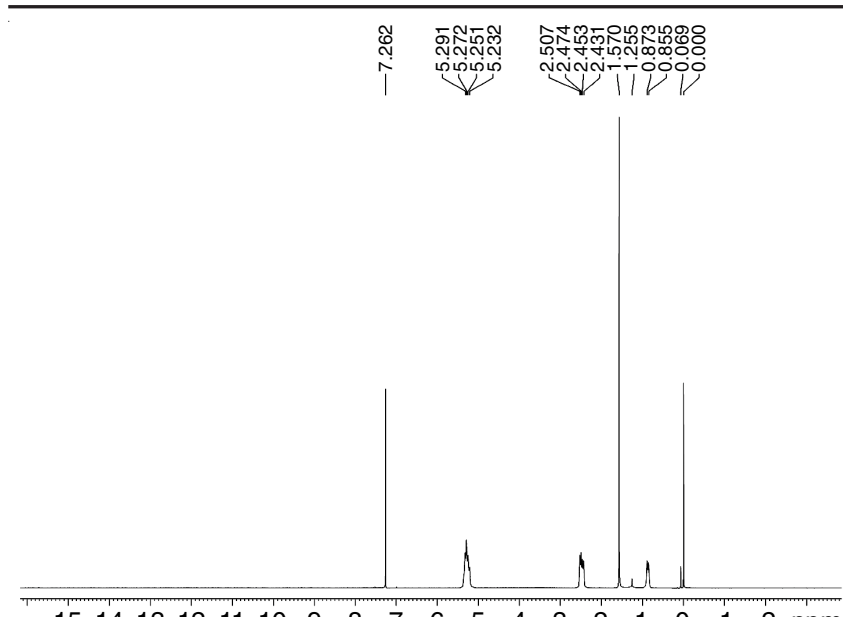

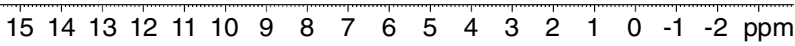

Fig. 3. ${ }^{1} \mathrm{H}$ NMR spectrum of biosynthesised PHB

(HB side group), $-\mathrm{CH}_{2}$ (HV and $\mathrm{HB}$ bulk structure) and $-\mathrm{CH}$ (HV and HB bulk structure) groups, respectively are shown in Fig. 3.

Thermal analyses: The composition of the polyesters was affected by the choice of substrate. A polyhydroxybutyrate homopolymer was produced from glucose or any other carbon sources. In the DSC thermogram (Fig. 4), the endothermic $T_{m}$ of PHB was observed at $172.01{ }^{\circ} \mathrm{C}$. This observation was also found to be in agreement with reported literature [22,23]. As shown in the Fig. 5, there is a relationship between the mixture of sugars and the polymer thermal stability in the gravimetric thermogram. For instance, feeding sugars mixture resulted in PHB polymer with TGA degradation temperature $\left(\mathrm{T}_{\mathrm{d}}\right)$ of 248.01 ${ }^{\circ} \mathrm{C}$. This observation was also found to be in agreement with the report of Liu et al. [23].

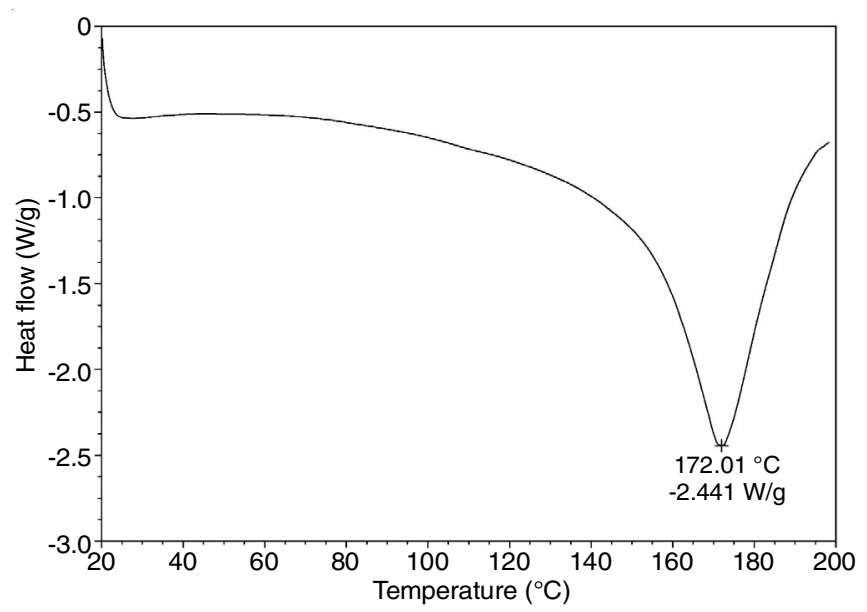

Fig. 4. DSC curve of biosynthesised PHB

\section{Conclusion}

Pre-treatment technique is the most important process for the extraction of sugar rich substrate from highly digestible biomass, which can be utilized for biosynthesis poly-3-hydroxybutyrate (PHB). In this study, the maximum yield of both the hexoses and pentoses were observed in hydrolyzate of Ulva obtained by $2 \% \mathrm{HCl}$ treated HTP. In this pre-treatment maximum glucose concentration of $53.21 \mathrm{~g} / 100 \mathrm{~g}$ total was obtained, than the other monosaccharide. Therefore, this hydrolyzate

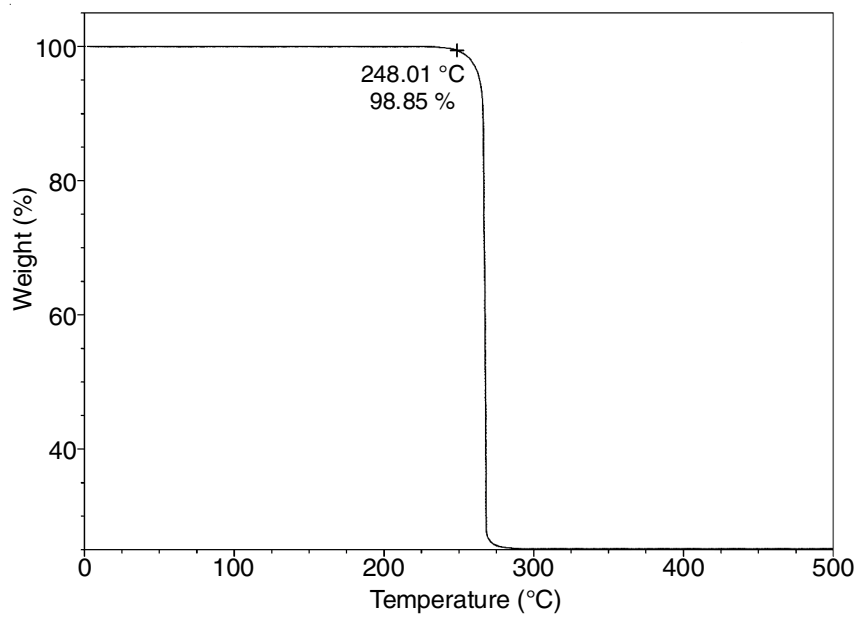

Fig. 5. TGA curve of biosynthesised PHB

was used for further PHB biosynthesis. The mutant bacterial strain B. subtilis rnM was able to grow and biosynthesis PHB, utilizing hydrolyzate of seaweed Ulva as the sole carbon and energy source. The maximum PHB $(43.41 \pm 0.11 \mathrm{~g} / \mathrm{L})$ was obtained from $2 \% \mathrm{HCl}$ treated at HTP hydrolyzate. The biopolymer PHB was conformed and estimated its melting temperature by FTIR, NMR and DSC, TGA, respectively. This study demonstrates the broadened possibility for improved low cost poly-3-hydroxybutyrate (PHB) biosynthesis through the utilization of waste sugars available from seaweed biomass.

\section{CONFLICT OF INTEREST}

The authors declare that there is no conflict of interests regarding the publication of this article.

\section{REFERENCES}

1. R. Davis, R. Kataria, F. Cerrone, T. Woods, S. Kenny, A. O’Donovan, M. Guzik, H. Shaikh, G. Duane, V.K. Gupta, M.G. Tuohy, R.B. Padamatti, E. Casey and K.E. O'Connor, Bioresour. Technol., 150, 202 (2013); https://doi.org/10.1016/j.biortech.2013.10.001.

2. R. Amache, A. Sukan, M. Safari, I. Roy and T. Keshavarz, Chem. Eng. Trans., 32, 931 (2013); https://doi.org/10.3303/CET1332156

3. A.K. Bhuwal, G. Singh, N.K. Aggarwal, V. Goyal and A. Yadav, Bioresour. Bioprocess, 1, 9 (2014); https://doi.org/10.1186/s40643-014-0009-5.

4. E. Markl, H. Grünbichler and M. Lackner, Nutr. Food Sci., 2, 1 (2018); https://doi.org/10.31031/NTNF.2018.02.000546.

5. N. Ceyhan and G. Ozdemir, Afr. J. Microbiol. Res., 5, 690 (2011).

6. https://cleantechnica.com/2018/07/31/demand-for-biodegradableplastics-expected-to-surge/

7. L.F. Silva, M.K. Taciro, M.E. Michelin Ramos, J.M. Carter, J.G.C. Pradella and J.G.C. Gomez, J. Ind. Microbiol. Biotechnol., 31, 245 (2004); https://doi.org/10.1007/s10295-004-0136-7.

8. P. Suriyamongkol, R. Weselake, S. Narine, M. Moloney and S. Shah, Biotechnol. Adv., 25, 148 (2007);

https://doi.org/10.1016/j.biotechadv.2006.11.007.

9. C. Nielsen, A. Rahman, A.U. Rehman, M.K. Walsh and C.D. Miller, Microb. Biotechnol., 10, 1338 (2017); https://doi.org/10.1111/1751-7915.12776.

10. J.L. Ienczak, W. Schmidell and G.M.F. deAragao, J. Ind. Microbiol. Biotechnol., 40, 275 (2013); https://doi.org/10.1007/s10295-013-1236-Z.

11. G.W. Maneveldt, Y.M. Chamberlain and D.W. Keats, Afr. J. Bot., 74, 555 (2008); https://doi.org/10.1016/j.sajb.2008.02.002. 
12. G. Bedoux, K. Hardouin, A.S. Burlot and N. Bourgougnon, Adv. Bot. Res., 71, 345 (2014); https://doi.org/10.1016/B978-0-12-408062-1.00012-3.

13. A. Peña-Rodríguez, T.P. Mawhinney, D. Ricque-Marie and L.E. CruzSuárez, Food Chem., 129, 491 (2011); https://doi.org/10.1016/j.foodchem.2011.04.104.

14. G.L. Miller, Anal. Chem., 31, 426 (1959); https://doi.org/10.1021/ac60147a030.

15. M. Koller, R. Bona, C. Hermann, P. Horvat, J. Martinz, J. Neto, L. Pereira, P. Varila and G. Braunegg, Biocatal. Biotransform., 23, 329 (2005); https://doi.org/10.1080/10242420500292252.

16. J.H. Law and R.A. Slepecky, J. Bacteriol., 82, 33 (1961).

17. M. Kato, H.J. Bao, C.K. Kang, T. Fukui and Y. Doi, Appl. Microbiol. Biotechnol., 45, 363 (1996); https://doi.org/10.1007/s002530050697.

18. W. Pan, J.A. Perrotta, A.J. Stipanovic, C.T. Nomura and J.P. Nakas, J. Ind. Microbiol. Biotechnol., 39, 459 (2012); https://doi.org/10.1007/s10295-011-1040-6.
19. S. Taghavi, C. Garafola, S. Monchy, L. Newman, A. Hoffman, N. Weyens, T. Barac, J. Vangronsveld and D. van der Lelie, Appl. Environ. Microbiol., 75, 748 (2009); https://doi.org/10.1128/AEM.02239-08.

20. S. Le Meur, M. Zinn, T. Egli, L. Thony-Meyer and Q. Ren, BMC Biotechnol., 12, 53 (2012); https://doi.org/10.1186/1472-6750-12-53.

21. S.V. Reddy, M. Thirumala and S.K. Mahmood, World J. Microbiol. Biotechnol., 25, 391 (2009); https://doi.org/10.1007/s11274-008-9903-3.

22. L. Ma, H. Zhang, Q. Liu, J. Chen, J. Zhang and G.Q. Chen, Bioresour. Technol., 100, 4891 (2009); https://doi.org/10.1016/j.biortech.2009.05.017.

23. Q. Liu, G. Luo, X.R. Zhou and G.Q. Chen, Metab. Eng., 13, 11 (2011); https://doi.org/10.1016/j.ymben.2010.10.004. 